\title{
The influence of a small amount of substances present in tissue on the optical spectrum of an immunosuppressive drug
}

\author{
M. Marzejon, ${ }^{* 1,2}$ and M. Jędrzejewska-Szczerska ${ }^{1}$ \\ ${ }^{1}$ Faculty of Electronics, Telecommunications and Informatics, Gdańsk University of Technology, G. Narutowicza \\ 11/12, 80-233 Gdańsk, \\ ${ }^{2}$ Institute of Physical Chemistry, Polish Academy of Sciences, Kasprzaka 44/52, 01-224 Warszawa
}

Received August 14, 2018; accepted August 25, 2018; published September 30, 2018

\begin{abstract}
In this paper, we describe how commonly present in tissue substances - sodium chloride and glucose - affect the optical spectrum of an immunosuppressive drug (Cyclaid ${ }^{\circledR}$ by Apotex). Prepared samples were investigated using a spectrophotometer in the spectrum range from $250 \mathrm{~nm}$ to $1100 \mathrm{~nm}$. The maximum wavelength shift calculated on the basis of measurement results is not bigger than the measurement wavelength step. So, it can be concluded that a small amount of sodium chloride or glucose does not influence the measurement and it is possible to apply spectrophotometry in a point-of-care sensor of the Cyclaid ${ }^{\circledR}$ by Apotex level.
\end{abstract}

Imunosuppressive drugs are the type of medicines which inhibit or block the activity of the immunologic system, e.g. Cyclosporine (CsA), Tacrolimus, Sirolimus [1]. These medicines are commonly used in rheumatoid arthritis, systemic lupus erythematosus, after transplant treatment, Crohn's disease, primary nephrotic syndrome, psoriasis, atopic dermatitis, autoimmune bullous disease and others [2-3].

For an immunosuppressive drug, the therapeutic dose is strictly defined. Moreover, even small deviations could cause ineffectiveness of therapy. For instance, for Cyclosporine too small a medicine level leads to the rejection of a transplant, but for too high a dosage it is toxic and leads to an increase of the risk of developing e.g. skin cancer [4]. Therefore, the detection of the level of an immunosuppressant drug is very important. Moreover, it will be desirable to elaborate a highly sensitive and simple method which could be applied in a simple device as a point-of-care sensor.

For now, commonly used for immunosuppressive medicines detection methods are HPLC (highperformance liquid chromatography) and RIA (radioimmunoassay). These methods are characterized as very exact and are commonly used in medical laboratories. Nevertheless, both HPLC and RIA, require very specific equipment and reagents, take a lot of time, and can be performed only by qualified workers [5]-[6]. For these reasons, the mentioned techniques are not suitable to apply in a point-of-care sensor.

The potential solution to this problem can be the use of photonic methods. Photonic methods, including classical spectroscopic techniques, are used in medicine, especially in laboratory diagnostic tests [7-10] and for imaging [11-14]. One of them, the absorption spectroscopy is a technique which gives information about energy absorbed by the investigated sample at a specified wavelength [15]. UV/VIS absorption is associated with electronic and vibrational excitation and transitions [16]. Absorption spectroscopy is very promising and could be a good background for developing a simple and relative chip point-of-care sensor. Moreover, a spectroscopy-based method for Cyclosporine level detection was elaborated and fully described. We have shown that the absorbance spectrum is significantly changing in the range from $250 \mathrm{~nm}$ to 290 $\mathrm{nm}$. Moreover, the maximum of the absorbance spectrum is red-shifted with an increase of the drug concentration level [17]. Nevertheless, the potential problems are the specificity of this method and other substances which are present in the sample and can influence the measurement result. The aim of this research is to initially assess the influence of small amounts of other substances on the drug optical spectrum, which is connected with the drug level in water-like biological fluids.

The samples were prepared by the solution of an immunosuppressive drug (Cyclaid $\AA$, produced by Apotex, in which the active substance is Cyclosporine), glucose $\left(\mathrm{C}_{6} \mathrm{H}_{12} \mathrm{O}_{6}\right)$ and sodium chloride $(\mathrm{NaCl})$ in water. These substances - sodium chloride and glucose, were chosen because of their natural presence in biological fluids. The sodium chloride concentration levels are $0.7 \%(\mathrm{w} / \mathrm{w})$ - very close to the isosmotic concentration level and $3.6 \%(\mathrm{w} / \mathrm{w})$ - above the isosmotic concentration level. The glucose concentration levels are $0.8 \%$ o (w/w) and $1.3 \%$ (w/w), which levels refer to correct glucose concentration level and hyperglycaemia. The samples were prepared in two steps. The first step was to prepare solutions in deionized water, according to Table 1. Solutions S1 and S7 are the reference samples containing only deionized water and the active substance, while in solutions $\mathrm{S} 2 \div \mathrm{S} 6$ and $\mathrm{S} 8 \div \mathrm{S} 12$, various concentrations of glucose and sodium chloride have been added to the deionized water and the active substance.

${ }^{*}$ E-mail: mmarzejon@ichf.edu.pl 
Table 1. Drug (Cyclaid ${ }^{\circledR}$ by Apotex), sodium chloride $(\mathrm{NaCl})$ and glucose $\left(\mathrm{C}_{6} \mathrm{H}_{12} \mathrm{O}_{6}\right)$ concentration levels in prepared samples. Samples: $\mathrm{S} 1$ and $\mathrm{S} 7$ are the reference samples. All concentrations are (w/w).

\begin{tabular}{l|ccc} 
Sample & Drug [\%] & $\mathrm{NaCl}[\%]$ & $\mathrm{C}_{6} \mathrm{H}_{12} \mathrm{O}_{6}[\%$ [\%] \\
\hline S1 (ref) & 0.44 & 0.0 & 0.0 \\
S2 & 0.44 & 0.7 & 0.0 \\
S3 & 0.44 & 3.6 & 0.0 \\
S4 & 0.44 & 0.0 & 0.8 \\
S5 & 0.44 & 0.0 & 1.3 \\
S6 & 0.44 & 3.6 & 1.3 \\
S7 (ref) & 4.45 & 0.0 & 0.0 \\
S8 & 4.45 & 0.7 & 0.0 \\
S9 & 4.45 & 3.6 & 0.0 \\
S10 & 4.45 & 0.0 & 0.8 \\
S11 & 4.45 & 0.0 & 1.3 \\
S12 & 4.45 & 3.6 & 1.3
\end{tabular}

Then, such prepared solutions were dropped into cuvettes (ratiolab ${ }^{\circledR}$ macro cuvets by Ratiolab). These cuvettes were chosen because they are single-use (which is important for future biological samples investigation), low-cost and their operative wavelengths range is relatively large.

The measurements were performed using a UV/VIS spectrophotometer (UV-9000 UV-VIS Double Beam Scanning Spectrophotometer by Shanghai Metash Instruments Co. LTD). The spectrophotometer uses two light sources: a Deuterium Lamp and a Tungsten Lamp, and a silicon photodiode as a detector. The light from the light sources passes through a monochromator and then a monochromatic light beam passes through the device. This monochromatic light beam is split for two beams, which passes through the samples: investigated sample and reference sample. Behind the sample, a photodetector collects the light which passed through the sample. The spectra measurement is achieved by repetition for each wavelength from the specified spectrum range [18].

In our experiments, absorbance measurements were performed in transmission mode, in a spectrum range from $250 \mathrm{~nm}$ to $1100 \mathrm{~nm}$ with $1 \mathrm{~nm}$ step. This spectra range was chosen for several reasons. First, the spectrum range was limited by the cuvettes and the spectrophotometer. Secondly, for the wavelengths shorter than $250 \mathrm{~nm}$, more absorption bands were observed and the signal-to-noise ratio was very low. Thirdly, the measurement conditions are in accordance with previous work [17] and allow a clear comparison of the results.

The setup was calibrated using two cuvettes filled with deionized water. The acquired value was related to the reference sample (deionized water). Each sample was measured ten times. Single sample measurement took below $90 \mathrm{~s}$. Measurements results are shown in Fig. 1.
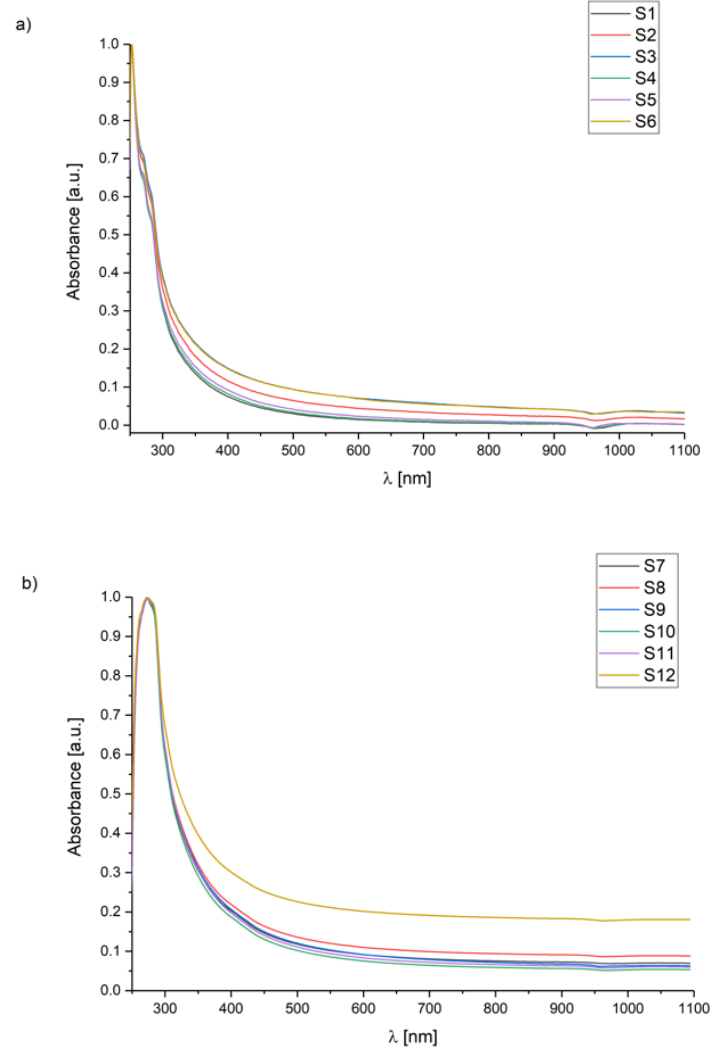

Fig. 1. Measurements results for a spectra range from $250 \mathrm{~nm}$ to $1100 \mathrm{~nm}$ and solutions: a) $\mathrm{S} 1 \div \mathrm{S} 6$, and b) $\mathrm{S} 7 \div \mathrm{S} 12$. Each curve was normalized separately. Samples description is in Table 1.

As we supposed, for the entire spectra range the absorbance level increases with an increasing concentration of $\mathrm{C}_{6} \mathrm{H}_{12} \mathrm{O}_{6}$ and $\mathrm{NaCl}$ for both drug concentration levels. Useful information about the drug concentration is encoded in the offset of the maximum of bands centres - the value of the peak wavelength.

It can be also observed (see Fig. 2), that the peak wavelength - the wavelength, for which the measured absorbance level takes the highest value, is almost the same for the reference sample - for samples $\mathrm{S} 1 \div \mathrm{S} 6$ as well as samples $\mathrm{S} 7 \div \mathrm{S} 12$. The peak wavelength deviations from the reference sample are summarized in Table 2.

Table 2. The peak wavelength deviation from the reference sample.

\begin{tabular}{l|ccccc} 
Sample & $\mathrm{S} 2$ & $\mathrm{~S} 3$ & $\mathrm{~S} 4$ & $\mathrm{~S} 5$ & $\mathrm{~S} 6$ \\
\hline $\begin{array}{l}\text { The peak wavelength } \\
\text { deviation }[\mathrm{nm}]\end{array}$ & 0.0 & 0.0 & 1.0 & 1.0 & 1.0 \\
\hline Sample & $\mathrm{S} 8$ & $\mathrm{~S} 9$ & $\mathrm{~S} 10$ & $\mathrm{~S} 11$ & $\mathrm{~S} 12$ \\
\hline $\begin{array}{l}\text { The peak wavelength } \\
\text { deviation }[\mathrm{nm}]\end{array}$ & 0.0 & 0.0 & 0.0 & 1.0 & 1.0
\end{tabular}




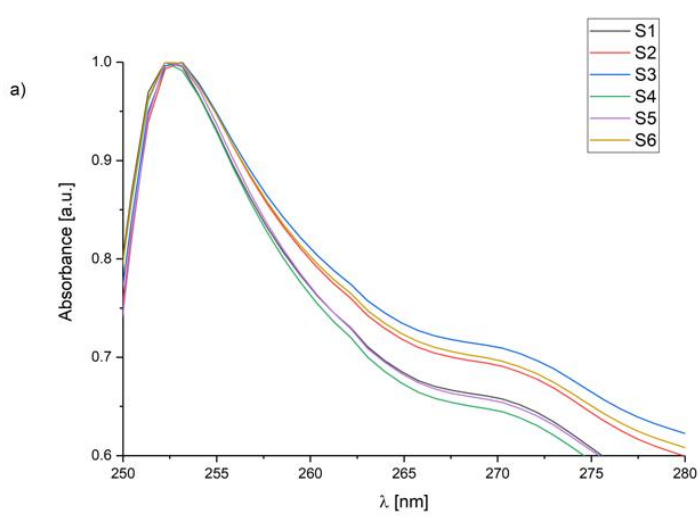

b)

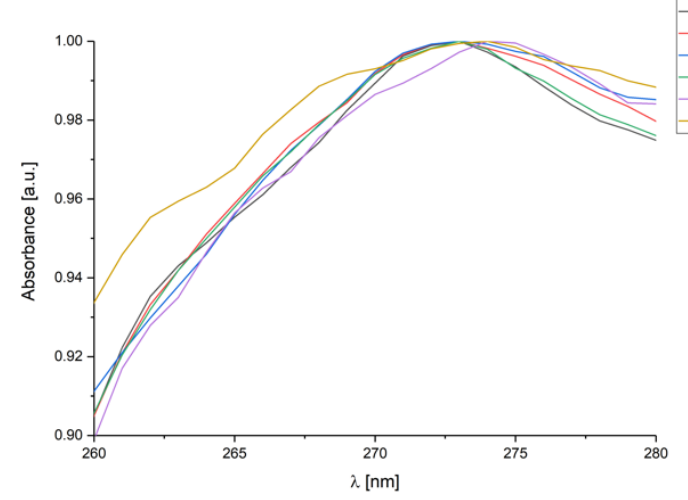

Fig. 2. Measurements results for a spectrum range from a) $250 \mathrm{~nm}$ to $280 \mathrm{~nm}$ for solutions $\mathrm{S} 1 \div \mathrm{S} 6$, and b) $260 \mathrm{~nm}$ to $280 \mathrm{~nm}$ for solutions $\mathrm{S} 7 \div \mathrm{S} 12$. Each curve was normalized separately. Samples description is in Table 1.

It can be observed that for samples $\mathrm{S} 1 \div \mathrm{S} 6$ and $\mathrm{S} 7 \div \mathrm{S} 12$ the peak wavelength deviation is not higher than $1 \mathrm{~nm}$ for a $1 \mathrm{~nm}$ measurement spectra resolution.

So it can be concluded that small concentrations of sodium chloride or glucose do not influence the measurement of Cyclosporine by spectrophotometry. It is very important for biological measurements because of small amounts of both organic and non-organic substances in human biological fluids similar to water, e.g. blood plasma, urine. In the light of this observation, it is possible to elaborate simple, non-invasive methods for measurements of selected parameters of biological fluids, which will be small, remote, and cheap and which could be applied as a point-of-care sensor. Nevertheless, more extensive researches in this field are required.

This study was supported by DS Programs of the Faculty of Electronics, Telecommunications and Informatics of the Gdańsk University of Technology.

\section{References}

[1] L. Taylor, C.J.E. Watson, J.A. Bradley, Crit. Rev. Oncol. Hematol. 56, 23 (2005).

[2] C.C. Mok, Best Pract. Res. Clin. Rheumatol. 31, 429 (2017).

[3] C.E.M. Griffiths et al., Br. J. Dermatol. 155, 1 (2006).

[4] F. Stucker, D. Ackermann, Ther. Umschau. Rev. Thérap. 68, 679 (2011).

[5] A. Fahr, Clin. Pharmacokinet. 24, 472 (1993).

[6] Cyclosporine-UpToDate, https://www.uptodate.com/contents/search?search=Cyclosporine \& submit $=$ Go

[7] P. Strakowska, R. Beutner, M. Gnyba et al., Mater. Sci. Eng. C. Mater. Biol. Appl. 59, 624 (2016).

[8] M. Gnyba, M.S. Wróbel, K. Karpienko et al., Proc. SPIE 9537, 95371N (2015).

[9] M.S. Wróbel, M. Gnyba, R. Urniaz et al., Proc. SPIE 9537, 95370Z (2015).

[10] M. Gnyba et al., Proc. SPIE 9448, 944809 (2015).

[11] H.S. Cho et al., Biomed. Opt. Expr. 5, 223 (2013).

[12] T. A. Valdez et al., Anal. Bioanal. Chem. 407, 3277 (2015).

[13] M. Ali Ansari, S. Alikhani, E. Mohajerani, Opt. Comm. 342, 12 (2015).

[14] M.S. Wróbel et al., J. Innov. Opt. Health Sci. 08, 1541005 (2015)

[15] D.A. Skoog, F.J. Holler, S.R. Crouch, Principles of instrumental analysis (Belmont, CA, Thomson Brooks/Cole 2007).

[16] M. Hof, Basics of Optical Spectroscopy in Handbook of Spectroscopy (Weinheim, Wiley-VCH Verlag GmbH \& Co. KGaA 2005).

[17] M. Marzejon et al, Sensors 18, 2001 (2018).

[18] UV-9000 Double Beam UV/VIS,

http://en.metash.com/ProductShow_172.html 